\title{
Academic involvement in Outreach: Best practice case studies from health and languages
}

\author{
Dr Patricia Harris, University of East Anglia, UK \\ Email: Patricia.Harris@uea.ac.uk \\ Dr Kim Ridealgh, University of East Anglia, UK \\ Email: K.Ridealgh@uea.ac.uk
}

\begin{abstract}
This paper will examine the role academic colleagues can play in the Widening Participation process (predominately outreach), by providing examples of innovative practice from the University of East Anglia. At the University of East Anglia a unique academic post is held in each Faculty to ensure that Widening Participation students are supported throughout their time at university and that subject-specific outreach sessions can utilise world-leading research to raise aspirations. This paper will highlight examples from Modern Foreign Languages and Health Sciences to demonstrate how academics can help raise aspirations and support long-term intervention projects. Norfolk is both a rural and costal county and faces difficult challenges in raising aspirations as some areas of the county have a progression rate to $\mathrm{HE}$ as low as $8 \%$. Thus, by creating a dynamic range of activities in collaboration with academic colleagues, a breadth of targeted activities can be delivered, activities that also benefit current UG students, academics, and support the reputation of the university itself.
\end{abstract}

Key words Widening Participation, Academic-led Outreach, Health Sciences, Languages.

\section{Overview and motivations}

In 2012 the University of East Anglia (UEA) introduced into its Access Agreement ${ }^{1}$ the provision of faculty specific outreach. This proviso supported the creation of four new academic posts (one for each of the main faculties), where the post holder would contribute not only to traditional academic activities within their faculty, but have a workload allocation to focus solely on the development, coordination and delivery of outreach activities and establishment of strategy within their faculty. UEA were among the first wave

\footnotetext{
${ }^{1}$ Sets out a university or college's fee limits and the access measures it intends to put in place e.g. outreach work and financial support. Any English institution wishing to charge above the current tuition fee threshold of $£ 6,000$ pa for full-time courses must have an approved agreement.
} 
of universities in England to create such posts and now, after nearly four years, can reflect on the benefit of such positions. This paper will highlight the key motivations behind creating such posts, why it was necessary that they should be academic-led, and the impact the post-holders have had within their subject areas via case studies from health and languages.

The motivations behind the creation of academic-led outreach posts were varied (some being faculty specific), but did focus around one main issue; the need to ensure that high-quality, subject-specific and research-led academic taster sessions were available to support and enhance aspiration-raising activity.

UEA has a varied and well-established catalogue of outreach programmes, which centre on strong relationships with target schools. These schools are identified via a basket of Widening Participation (WP) measures including Low Participating Neighbourhood (LPN) ${ }^{2}$, pupil premium ${ }^{3}$ and historical rates of progression to UEA. Certain outreach programmes are targeted at individual students, rather than schools, who meet the following contextual criteria: LPN, pupil premium, in care status, school attended, and household income. The aims of the activities, following Office For Fair Access (OFFA) guidelines, are to ensure that WP students have an understanding of what university entails and that those students who have the potential to achieve tariff grades are provided with necessary support (The Sutton Trust, 2008).

The inclusion of research-led academic taster sessions adds to these activities, providing important subject-specific content, helping not only to raise aspirations, but also providing young people with a realistic overview of what university will be like (Gazeley and Aynsley, 2012; Purcell et al., 2008). Successful taster sessions ideally form links between the curriculum at secondary and tertiary level to demonstrate the wider subject possibilities at university, and their impact on future careers, or support the development of key transition skills that will improve an individual's application or journey into HE. For example, a taster session from languages includes utilising oral skills whilst learning more about the day-to-day activities of an interpreter. This not only highlights the degree course and career opportunities, but allows students to practically use their language skills in an immersive setting. One of the taster sessions for health sciences focuses on developing communication skills, which will be tested during application to HE, and

\footnotetext{
${ }^{2}$ The Higher Education Funding Council for England (HEFCE) has produced a means of grouping areas across the UK based on the proportion of the young population that participates in HE. Five groups exist and LPN represents the lowest quintile group. (http://www.hefce.ac.uk/analysis/yp/POLAR/).

${ }^{3}$ Pupil premium is additional funding for publicly funded schools in England to raise the attainment of disadvantaged pupils and close the gap between them and their peers (https://www.gov.uk/guidance/pupil-premium-information-for-schools-and-alternativeprovision-settings).

${ }^{4}$ The independent regulator of fair access to HE in England (https://www.offa.org.uk/).
} 
links the skills to the role of health professionals using a simulated scenario where students play the parts of the patient and the health professional.

The above requires a large amount of engagement from each Faculty to ensure accurate representation of each subject. Encouraging faculties to take ownership of certain outreach activities was something that was deemed to be best supported by an academic from within. It required an academic with both prior outreach experience and wider enthusiasm for working with young people; yet someone who also understood academic expectations and responsibilities. The risk here is that there may be a single point of fail and to minimise this the post holders have tried to create a sustainable outreach programme integrated into Faculty recruitment policies. Part of this has involved the post holders creating networks of colleagues willing to deliver sessions, university-wide training programmes for staff development, as well as professional development training for $\mathrm{PhD}$ students. By encouraging $\mathrm{PhD}$ students to understand the importance of outreach and the reasons why universities must deliver an outreach agenda, and supporting them to create and deliver workshops of their own, it ensures that a new generation of academics have experience, and, more importantly, the desire, to continue to promote outreach activity throughout their academic careers. A sustainable outreach agenda is essential in counties like Norfolk that have large pockets of intercity, rural, and coastal LPNs.

There have been further positive, yet unpredicted, benefits arising from the academic outreach posts. Firstly, that the post holders are able to act as intermediates between their home Faculties and the wider central administration, bridging the gap between the two and managing expectations on both sides. This has resulted in an increased rate of engagement and a streamlining of communication channels. Secondly, via the post holders providing targeted advice to academic colleagues, there has been an increase in the number of outreach activities included in funding applications and a better understanding of how outreach can support academic promotion (for example, outreach activities can be classed as engagement). Thirdly, the post holders have been able to utilise their research and academic skill set to help improve targeting and evaluation of university-wide outreach projects, contribute to the Access Agreement, promote outreach activities at conferences and within published works, and ensure that outreach can be included in assessment measures, such as the Research Excellence Framework (REF). The case studies included in the examples below, taken from the Schools of Health Sciences and Politics, Philosophy, Language and Communication Studies, provide a more detailed explanation of these activities. One thing immediately noticeable is that outreach activities conducted by the Academic Outreach post holders focus more on transitionbased outreach, encouraging and supporting young people to progress in a particular subject area; rather than generic outreach aspiration-raising activities. 


\section{Case study from health sciences}

Within the School of Health Sciences, students train to be a variety of health professionals. The nature of these vocational courses, and the government funding that has traditionally been available, has made them an attractive option for both young and mature individuals from WP backgrounds. Internal $2014 / 15$ data from UEA shows that $18.1 \%$ of students studying on health courses are from the lowest LPN quintile; for nursing this increases to $24 \%$.

Although Health Sciences are popular courses for WP students (in particular those from low-income backgrounds, mature students and first in their family to study at HE), there is still a large gap in the awareness of particular professions. There is also wide spread misconceptions around the prerequisite care experience required to be a successful applicant. The same extends to courses such as Medicine and Social Work; The Medical Schools Council (MSC; 2014) highlighted this extensively in their Selecting For Excellence Guidance. The lack of awareness around particular professions and misunderstandings of the experience required can be a barrier to progression to $\mathrm{HE}$, and retention once at $\mathrm{HE}$, and these are areas that have been heavily addressed by the Academic Outreach post through both student workshops, teacher training and the creation of specific literature.

In regards to the two points above, low awareness of certain professions and misconceptions around aspects of the entry requirements, Health Sciences introduced an outreach support package. It identifies students interested in health from UEA's pre-16 outreach programmes, invites them to participate in a discipline specific Year 12 summer school, and then follows them through application to interview. This longitudinal approach, coordinated by the Academic Outreach post holder, starts with academic input into discipline specific taster sessions for pre-16 outreach programmes, development of post-16 discipline-specific residentials and coordination of application and interview support. This ensures the aspiration raising pre-16 programmes cover the breadth of disciplines available and that the post-16 content is representative of specific courses and supports applications. Accurate representation of the course is extremely important because of the intense nature of the health professional degrees and the high risk of attrition if students' expectations do not align with the reality (Thomas, 2012; Moore, Sanders and Higham, 2013). Realistic taster sessions are best delivered by academics involved or very close to the pre-registration courses. The nature of the admissions process, which requires recruitment to National Health 
Service (NHS) values ${ }^{5}$, means it is unique within the University and Faculty driven; thus academic input is essential to accurately represent this part of the admissions process. It is therefore important that academic-led provision from within the Faculty is utilised to support WP progression, success and retention.

Although WP statistics for Health Sciences are generally good, the recent government review of health education funding (Department of Health, 2016), which sets out changes from bursaries to loans ${ }^{6}$, has the potential to threaten this. The Faculty-based Academic Outreach post has facilitated the central Outreach team and the School of Health Sciences to be proactive in addressing the incoming changes by communicating and sharing practice and information across the university. For example, being permanently situated within the Faculty and working with executive members allowed for earlier insights into the changes to be disseminated to the central team. Additionally, by working directly with current undergraduates and secondary school students a greater understanding of the concerns surrounding the changes has be gained and used to plan future outreach provision. This allows actual concerns, of both young and mature students, to be addressed rather than perceived concerns. Via the post holder's inclusion in the central Outreach and Admissions teams, wider knowledge of how funding works for the rest of the university, already on the loan system, could be speedily communicated to the School to inform staff who previously required no knowledge of this. As a result we have been able to quickly look at the problem from multiple angles, including the School, central, current and prospective students' perspectives, and begin to draw holistic solutions and share information via existing channels. An integrated Outreach Academic post can, therefore, be instrumental in reacting to sector changes and can facilitate information sharing both internally and externally.

Data suggests that the move to student loans for other non-health courses has not reduced the numbers of students applying from lower socio-economic groups and in fact an increase in WP students entering HE has been seen (NEON, 2015). This was alluded to by the Council of Deans (2015) early in the reform process. However, this phenomenon was likely because changes in funding were being paralleled by WP efforts, including increased outreach from HEIs, external companies, government and charities. The evidence would therefore suggest that if we, as a health education provider, are

\footnotetext{
${ }^{5}$ The values outlined in the NHS Constitution include: Respect and dignity, Commitment to the quality of care, Compassion, Improving lives, Working together for patients, Everyone counts.

${ }^{6}$ Health students in England currently pay no tuition fees and are in receipt of NHS bursaries. Form August 2017 new students will no longer receive NHS bursaries and will be liable for tuition costs, instead, they will have access to the same student loans system as other students. Loans for tuition fees and living costs are repaid once in employment and earning above the threshold (currently $£ 21,000$ ).
} 
proactive in our outreach activity and disseminate accurate information about i) the way in which courses are funded and loans repaid, ii) the resulting qualification and earning potential of a health professional and iii) support applicants to better understand finance and budgeting, then we may not experience a reduction in WP applicants. An increase in this activity requires an institutional and sector-wide approach, where Health Schools, central teams and local NHS Trusts collaborate to support applicants.

\section{Case study from languages}

Across England, university language departments are facing a downward trend in the number of applications for their undergraduate degree programmes. Since 2003 there has been a 16\% decrease in entrants for these degrees (HESA, 2015), primarily caused by the overall decline in students taking a language at both Level 2 and 3 (Tinsley \& Han, 2012: 4; Malpass, 2014). A variety of different factors are contributing to this national decline in young people choosing to study a language a secondary level, even though language provision at primary level is more widespread (the Language Trends Survey 2014/15 (CiLT, 2015) indicates that languages are taught in 99\% of their surveyed primary schools at KS2 level). Factors include a lack of qualified teachers, optionality disappearing from schools, reduction in provision and resources, and the failure of the English Baccalaureate to fully engage young people with languages (Taylor \& Marsden, 2014: 905). This is a major contributing factor to the decline in language studies, the fact that the majority of young people are unable to bridge the gap between the relevance of language learning in their own lives and future employment, and the enjoyment of learning a language (Burge et al., 2013). The difficulty of motivating students in relation to languages was highlighted as a 'major challenge' by $63 \%$ of state schools surveyed in the Language Trends report 2015 (CiLT, 2015) versus 34\% of schools from the independent sector

A growing concern with language provision across England is the perceived divide emerging between low and high attaining schools (CiLT, 2010). According to Claussen (2003: 6), this is due to the fact that languages after Key Stage 3 (KS3; pupils usually aged 14 years and up) ${ }^{7}$ are optional, making independent schools and selective state schools almost the only institutions able to offer languages to all students. Additionally, private and high attaining state schools are more likely to provide additional resources for language teaching and have a better understanding of the wider skills languages provide, such as cultural awareness. The Language Trends 2015 report (CiLT, 2015) found direct correlations between socio-economic disadvantage and restricted access to languages; it was found that the lowest

\footnotetext{
${ }^{7}$ The state education system in England, Wales and Northern Ireland has 6 Key Stages (KSO-KS5) which set out the educational knowledge expected of students at various ages.
} 
attaining category of schools excluded $17 \%$ of pupils from language study in KS3 and $44 \%$ at KS4.

With growing difficulties emerging in language retention and motivation, there is now a pressing need to not only perform targeted outreach activities for languages, but ensure that the activities are specifically aspiration raising for students from LPNs. In order to do this it was necessary to ensure that outreach activities were planned based on a wider understanding of the current difficulties in retaining students, and in consultation with teachers. In order to engage with teachers, the UEA Language Teachers' Network was established. The Network provides regular email updates to teachers about language initiatives at UEA, as well nationally, and meets three times a year to discuss wider issues in the sector, such as good practice, and allows invited speakers to provide more focus information to teachers on a related theme, such as curriculum reform and marking issues. This Network now comprises of almost 70 language teachers from schools across Norfolk and Suffolk and has allowed UEA to establish strong collaborative relationships with the teachers involved. On consultation, when asked what type of activities would benefit their school the most, the response from teachers was i) to raise the profile of languages; ii) reinforce the employability of languages; iii) something exciting and different. By working with teachers and targeting activities to their needs, it has meant that delivering activities in schools has been aided by strong teacher support. The Network also allows teachers direct access to the Outreach Academic coordinating the language outreach programme, increasing the overall amount of requests for activities. By employing this method, it has been possible to increase the number of young people engaging with language-based outreach, from around 200 per year in $2012 / 13$ to nearly 3000 in 2015/16.

Thanks to strong financial support from UEA, AHRC and Routes into Languages, the Outreach Academic was able to establish a range of languagebased outreach activities, which are designed to engage students at different periods of the transition throughout secondary education. These include language ambassador schemes and language taster days, but also UEAspecific long-term classroom support for oral skills, an A-level (level 3) revision day, language summer school, and an employability language and intercultural communication-based activity called the Language of Business. Together these activities form part of a REF impact case study, assessing whether the intervention projects/activities are successful in supporting the retention and progression of young people (Years 7-13) in MFL. As per the REF requirements, impact needs to be evidenced and we have done this by requesting each student to complete a questionnaire, asking their opinions before and after the intervention. Although the results will be fully published elsewhere, two key points were discovered in the pilot round of data collection (approx. 600 participants). Firstly, that although outreach target schools were predominantly the main participants in the intervention 
activities, there was at times a limited number of LPN students included, possibly reflecting the divide in attitudes to languages or language provision, but certainly indicating the need to improve targeting. Secondly, it was possible to measure that after each intervention activity, there was at least a $10 \%$ increase in the number of young people saying that they would like to continue studying a language at the next level. It was also possible to notice a positive increase in the number of students who stated that before the activity they did not wish to study a language further to afterwards being unsure about studying a language, further supporting the need for long-term engagement.

\section{Concluding remarks}

The aim of this paper is to highlight the benefit of academic involvement in a successful and sustainable outreach programme. By ensuring committed academic involvement, the central Outreach team at UEA and students from WP backgrounds have benefited from specialised information, support in specific subject areas, and a long-term commitment to WP in the Faculties. However, the establishment of Faculty-based Academic Outreach posts do take time to embed, and UEA was forward thinking in establishing such posts in 2012, prior to the announcement of the Teaching Excellence Framework ${ }^{8}$. A quicker way of creating the beneficial connections between Faculties and Outreach may be to buy out proportions of carefully chosen, existing academics' time. The caveat here, however, is that the outreach role is quite time consuming and a careful balance must be struck between academic and outreach workload. Collaborative recruitment between the Faculty and Outreach of the post holders must occur to ensure a suitable individual is placed within these positions, and clear line-management/operational management should exist to improve the effectiveness of such posts. However, the long-term benefits of the integrated posts demonstrated at UEA, outweigh any short-term discomfort of implementing and embedding the posts within Faculties.

\footnotetext{
${ }^{8} \mathrm{~A}$ new form of monitoring which is being introduced by the Government to assess the quality of teaching in England's universities.
} 


\section{References}

Claussen, I. (2003) Widening Participation and Ensuring Success. Transition from A-level to University: A Report Based on the Experiences of Students and Staff in the School of Modern Languages at Queen Mary, University of London. Department of External Relations and Communications. [Online]. Available at https://www.llas.ac.uk/resources/paper/2236 (accessed 3 February 2016).

CiLT. (2010) Language Trends 2010. [Online]. Available at http://www.alcantaracoms.com/wp-content/uploads/2014/05/LanguageTrends-2010_Final-Report.pdf (accessed 3 February 2016).

CiLT. (2015) Language Trends 2015. [Online]. Available at https://www.britishcouncil.org/sites/default/files/language_trends_survey_201 5.pdf (accessed 3 February 2016).

Council of Deans (2015) A Call for Funding Reform: Answering key questions. Available at http://www.councilofdeans.org.uk/2015/07/a-call-for-fundingreform-answering-key-questions/ (accessed 9 May 2016).

Department of Health (2016) NHS bursary reform. Available from: https://www.gov.uk/government/publications/nhs-bursary-reform/nhsbursary-reform (accessed 16 September 2016).

Gorard, S., Smith, E., May, H., Thomas, L., Adnett, N., Slack, K. (2006) Review of widening participation research: Assessing the barriers to participation in higher education, (Bristol, HEFCE). Available from http://dera.ioe.ac.uk/6204/1/barriers.pdf (accessed 19 May 2016).

Gazeley, L. and Aynsley, S. (2012) The Contribution of Pre-entry Interventions to Student Retention and Success. York: Higher Education Academy. Available at:

http://www.heacademy.ac.uk/resources/detail/WP_syntheses/Gazeley_Aynsle y (accessed 15 April 2016).

HESA. (2015) Higher Education Statistics for the UK. [Online]. Available at http://www.hefce.ac.uk/analysis/supplydemand/ug/ (accessed 3 February 2016).

Malpass, D. (2014) The Decline in Uptake of A-level Modern Foreign Languages: Literature Review. Joint Council for Qualifications, 1-27. Available at http://www.jcq.org.uk/media-centre/news-releases/chapter-1---the-decline-inuptake-of-a-level-modern-foreign-languages-literature-review (accessed 15 April 2016).

Medical Schools Council (2014) Work experience guidelines for applicants to medicine. Part of Selecting for Excellence. Available at http://www.medschools.ac.uk/SiteCollectionDocuments/Work-experienceguidelines-for-applicants-to-medicine.pdf (accessed 19 May 2016)

Moore, J., Sanders , J. and Higham, L.(2013) Literature review of research into widening participation to higher education. Available at: 
https://www.offa.org.uk/wp-content/uploads/2013/08/Literature-review-ofresearch-into-WP-to-HE.pdf (accessed 10 April 2016)

NEON, (2015) Does Cost Matter? Students' understanding of the higher education finance system and how cost affects their decisions. Available at: http://www.educationopportunities.co.uk/wpcontent/uploads/DoesCostMatter_ANEONReport.pdf (accessed 16 September 2016).

Purcell, K., Ellison, R., Atfield, G., Adam, D. and Livanos, I. (2008) Applying for Higher Education - The Diversity of Career Choices, Plans and Expectations. Manchester: HECSU. Available at: http://www.hecsu.ac.uk/assets/assets/documents/Applying_for_higher_educat ion.pdf (accessed 15 April 2016).

Taylor, F. and Marsden, E. J. (2014) Perceptions, Attitudes, and Choosing to Study Foreign Languages in England: An Experimental Intervention, The Modern Language Journal, 98, 4: 902-920.

The Sutton Trust (2008) Increasing Higher Education Participation amongst Disadvantaged Young People and Schools in Poor Communities. Available at: http://www.suttontrust.com/wpcontent/uploads/2008/10/1NCEE interim report.pdf (accessed 15 April 2016).

Thomas, L. (2012) What works? Facilitating an effective transition into higher education. Widening Participation and Lifelong Learning, 14, 4-24.

Tinsley, T. and Han, Y. (2012) Language Learning in Secondary Schools in England: Findings from the 2011 Language Trends Survey. [Online]. Available at http://cdn.cfbt.com/ /media/cfbtcorporate/files/research/2012/rlanguage-learning-in-secondary-schools-in-england-language-trends-2012.pdf (accessed 15 April 2016). 